\title{
Implant-Free Subpectoral Biceps Tenodesis Is Biomechanically at Higher Risk of Spiral Fracture of the Humerus Compared With Implant-Free Suprapectoral Biceps Tenodesis
}

\author{
Arash A. Dini, M.D., Joshua E. Mizels, B.A., Sohale Sadeghpour, M.D., \\ Michael J. O'Brien, M.D., Felix H. Savoie III, M.D., and Mark H. Getelman, M.D.
}

Purpose: To compare the likelihood of spiral fracture of the humerus using torsional load to failure after intraosseous biceps tenodesis at the position of the arthroscopic suprapectoral tenodesis versus the subpectoral meta-diaphyseal location. Methods: Eight matched pairs of humeri were dissected. Unicortical tenodesis holes were drilled, either at the bottom of the bicipital groove (group 1) or just below the pectoralis major tendon insertion (subpectoral) in the humeral diaphysis (group 2). Tenodesis was performed in a 7-mm bone tunnel, with suture fixation distal to this site using 2 separate 2 -mm holes, secured with No. 2 polyester suture. Each humerus was potted in plaster and mounted to a hydraulic torsional load frame, consistent with previously validated models for creating humeral spiral fractures. External rotation torque was applied to each humerus distally until fracture occurred. The paired $t$ test was used to compare the 2 groups. Results: Fracture occurred at the subpectoral cortical drill hole in all 8 specimens in group 2. In group 1, only 2 fractures occurred through the tenodesis hole, with spiral fracture resulting in the diaphysis of the humerus in 6 of 8 specimens. Average torque to failure measured $31.35 \mathrm{Nm}$ in group 1 and $25.08 \mathrm{Nm}$ in group 2; the difference was statistically significant $(P<.0001)$. Conclusions: Subpectoral cortical drill holes for biceps tenodesis were shown to be a stress riser for humeral spiral fracture. Suprapectoral cortical drill holes were shown to be significantly less of a stress riser. The amount of torque required to fracture the humerus through the subpectoral drill holes was less than with the suprapectoral drill holes. Only 2 fractures occurred through the suprapectoral tenodesis holes, and significantly more torque was required to create these fractures. Clinical Relevance: Clinically, the difference between suprapectoral and subpectoral tenodesis fracture potential should be considered when selecting a tenodesis location.

$\mathbf{P}$ ain has long been associated with the proximal attachment of the biceps tendon in the shoulder. Although the biceps tendon's exact role in shoulder function continues to be the subject of debate, its role as a pain generator has been well established. ${ }^{1,2}$ Tenodesis of the long head of the biceps to either bone or soft tissue is the preferred surgical treatment for refractory tendinosis and other pathology of the long head of the

From Private Practice, Encino, California, U.S.A. (A.A.D.); Morsani College of Medicine, University of South Florida, Tampa, Florida, U.S.A. (J.E.M.); Memorial Hermann Memorial City Medical Center, Houston, Texas, U.S.A. (S.S.); Department of Sports Medicine, Tulane University, New Orleans, Louisiana, U.S.A. (M.J.O., F.H.S.); and Southern California Orthopedic Institute, Van Nuys, California, U.S.A. (M.H.G.).

The authors report the following potential conflicts of interest or sources of funding: M.J.O. is a paid consultant for Smith $\theta$ Nephew and Stryker, outside the submitted work. M.H.G. receives consultation fees from DePuy Mitek; receives institutional support from DePuy Mitek and Smith $\theta$ Nephew; and receives royalties from Wolters Kluwer, outside the submitted work. Full biceps tendon in the young and active patient. ${ }^{3}$ However, several case reports have been published citing spiral fractures of the humerus after subpectoral bony biceps tenodesis, with the location of the screw placement implicated as a stress riser for fracture..$^{4-7}$ All of the fractures documented in the literature occurred in patients receiving subpectoral tenodesis with cortical intraosseous tunnels and screw fixation. Additionally,

ICMJE author disclosure forms are available for this article online, as supplementary material.

Received December 10, 2019; accepted August 26, 2020.

Address correspondence to Mark H. Getelman, M.D., Southern California Orthopedic Institute, 6815 Noble Ave, Van Nuys, CA 91405, U.S.A. E-mail: mgetelman@scoi.com

(C) 2020 THE AUTHORS. Published by Elsevier Inc. on behalf of the Arthroscopy Association of North America. This is an open access article under the CC BY-NC-ND license (http://creativecommons.org/licenses/by-nc-nd/4.0/). 2666-061X/19224

https://doi.org/10.1016/j.asmr.2020.08.011 
subpectoral biceps tenodesis with an interference screw has been shown to increase the risk of humeral spiral fracture compared with intact humeri regardless of screw size. ${ }^{6}$

Although a variety of options for humeral fixation exist (bone tunnels, suture anchors, interference screws, and so on), intraosseous fixation with or without implants has gained popularity as an option for fixation of the tendon to the humerus using both open and arthroscopic techniques. ${ }^{8}$ At our institutions, placement of the tenodesis at the inferior aspect of the bicipital groove above the pectoralis major tendon (suprapectoral) is the preferred location for an arthroscopic technique. Placement of the tenodesis just distal to the pectoralis tendon (subpectoral) is the typical location for a mini-open technique. In either location, one of the senior authors (M.H.G.) prefers to use a biomechanically validated implant-free intraosseous tendon fixation method.

The purpose of our study was to compare the likelihood of spiral fracture of the humerus using torsional load to failure after intraosseous biceps tenodesis at the position of the arthroscopic suprapectoral tenodesis versus the subpectoral meta-diaphyseal location. We hypothesized that the humeri with the subpectoral biceps tenodesis procedure would be at greater risk of spiral fracture than the humeri with the suprapectoral biceps tenodesis procedure using the same technique, making the humeral tunnel location the only variable.

\section{Methods}

\section{Group Identification}

Eight matched pairs of fresh-frozen humeri and biceps tendons $(\mathrm{N}=16)$ were obtained from donors through the United Tissue Network (Phoenix, AZ). All specimens were from male cadavers, with a mean age of 58 years (range, 45-74 years). Because this was a cadaveric study, all specimens with an intact long head of the biceps tendon were included. There were no exclusions based on size, age, sex, or side. The pectoralis major tendon was identified and preserved; all other soft tissues were removed. The humeri were randomized into groups by coin flip. The right humeri were designated group 1 and underwent suprapectoral tenodesis, and the left humeri were designated group 2 and underwent subpectoral tenodesis. We took into consideration that the bone mineral density (BMD) might be different between the groups, but studies showing a significant effect of hand dominance on BMD are limited. In fact, Sergi et al. ${ }^{9}$ (2009) showed that there is no significant effect of hand dominance on BMD.

\section{Surgical Technique}

Unicortical 7-mm holes were drilled in either of the 2 locations (Fig 1): at the inferior aspect of the bicipital groove just distal to the ridges and proximal to the pectoralis tendon (group 1, suprapectoral) (Fig 2) or just

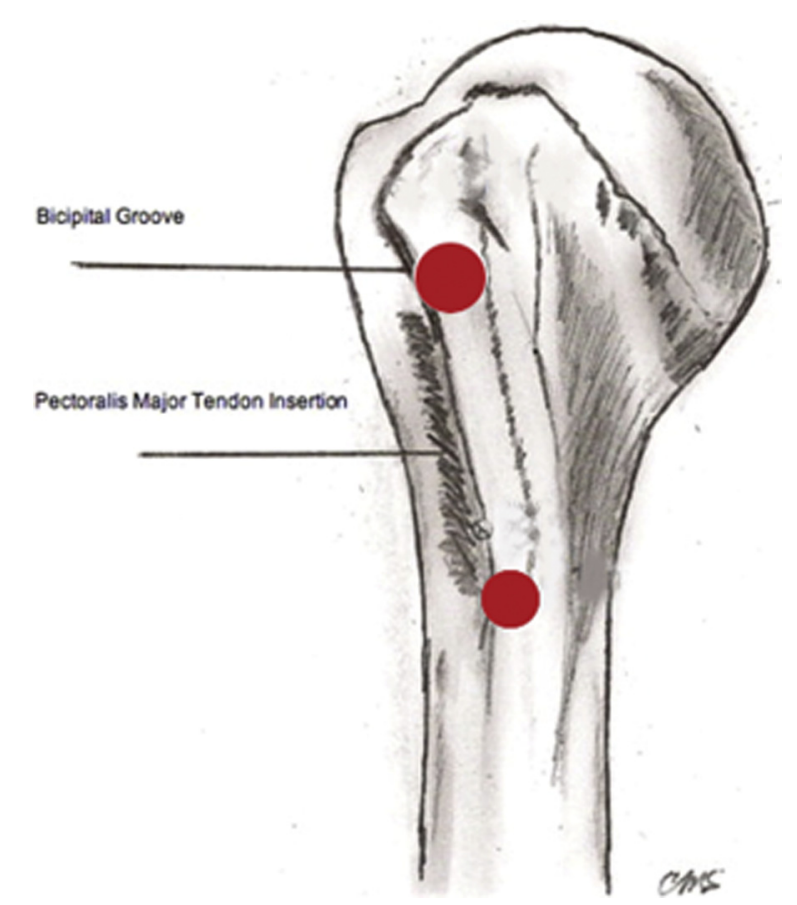

Fig 1. Anatomic location of both bicipital groove and subpectoral tenodesis screw placement (red circles).

distal to the pectoralis major tendon insertion in the humeral diaphysis (group 2, subpectoral) (Fig 3). The instrumentation used was the same as that used in the operating room for a 7-mm intraosseous tenodesis hole (Smith \& Nephew, London, England). Two sutureshuttling holes ( $2 \mathrm{~mm}$ in size) were drilled $15 \mathrm{~mm}$ distal to the tenodesis hole, with these suture-shuttling holes being placed $6 \mathrm{~mm}$ apart (Fig 4). The corresponding biceps tendon to each humerus was then passed intraosseously and underwent tenodesis after a locking suture was applied to the tendon and then shuttled through the drill holes, as previously described by Sampatacos et al. ${ }^{10}$

\section{Biomechanical Testing}

Each humerus was potted in plaster and mounted to a hydraulic torsional-axial load frame (MTS Systems, Eden Prairie, MN), consistent with previously validated models for creating humeral spiral fractures. ${ }^{11}$ Once mounted, each humerus was conditioned on the load frame with sinusoid cycles of torsion of 0.5 to $6.5 \mathrm{Nm}$ at $0.1 \mathrm{~Hz}$ for 1,000 cycles. After conditioning, torsional external rotation torque was applied to each humerus distally in a linear ramp function, starting at $0.1 \mathrm{Nm}$ and advancing until fracture at a rate of $0.1 \mathrm{Nm} / \mathrm{s}$. Data were recorded at the maximum torque applied until fracture or failure of the construct.

\section{Statistical Analysis}

The data were evaluated for differences in torque between the suprapectoral (group 1) and subpectoral (group 2) tenodesis locations. Data were analyzed by 


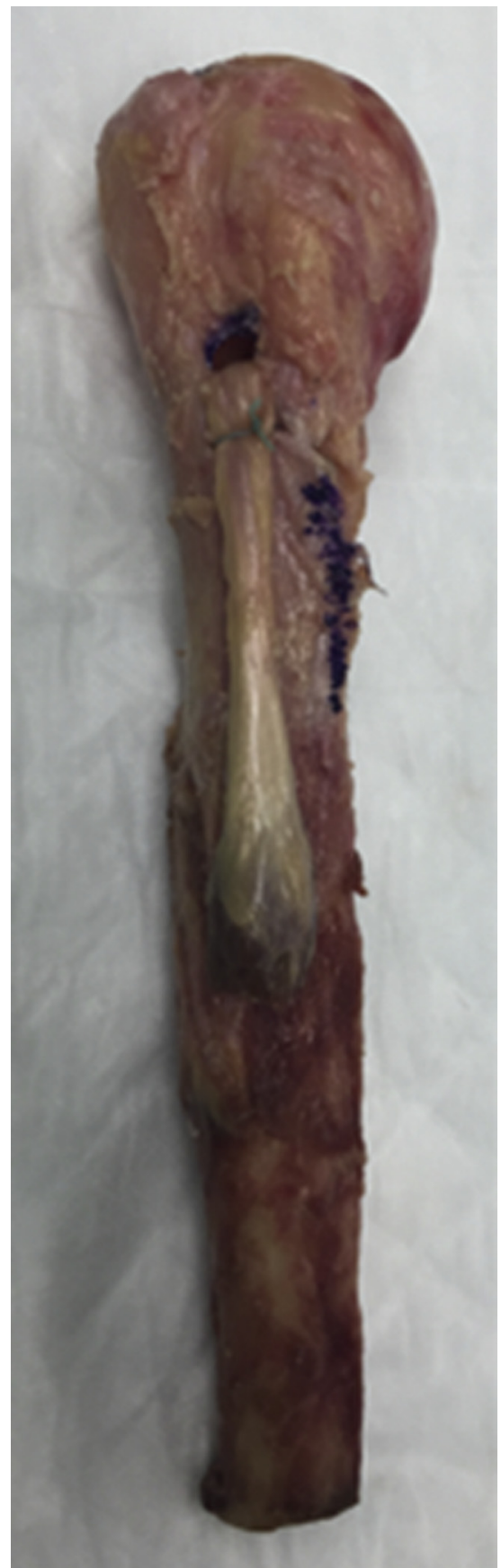

Fig 2. Tenodesis placed at inferior aspect of bicipital groove, just distal to ridges and proximal to pectoralis tendon, in a right shoulder.

the 2-tailed paired $t$ test, with the level of significance set at $P<.05$.

\section{Results}

In the suprapectoral group, only 2 fractures occurred through the suprapectoral cortical drill holes, with spiral fracture resulting in the diaphysis of the humerus in the remaining 6 of 8 specimens (group 1). Fracture occurred at the subpectoral cortical drill holes in all 8 specimens in group 2 (Fig 5). Average torque to failure measured $31.35 \pm 2.76 \mathrm{Nm}$ in group l (suprapectoral) and $25.08 \pm 2.18 \mathrm{Nm}$ in group 2 (subpectoral) (Fig 6). The difference between these values was statistically significant $(P<.0001)$.

\section{Discussion}

The results of our study suggest that a suprapectoral approach may be biomechanically superior to a subpectoral approach for treating biceps tendinopathy. A recent review showed an overall $2.0 \%$ complication rate

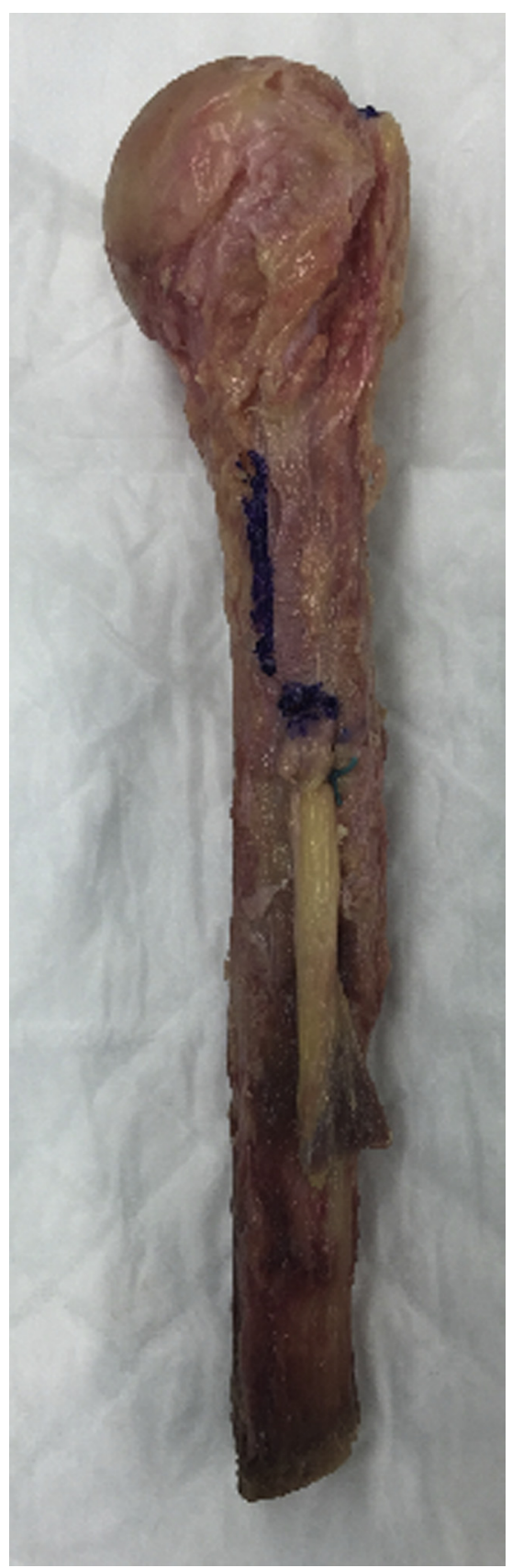

Fig 3. Tenodesis placed just distal to pectoralis major tendon insertion in humeral diaphysis in a left shoulder. 


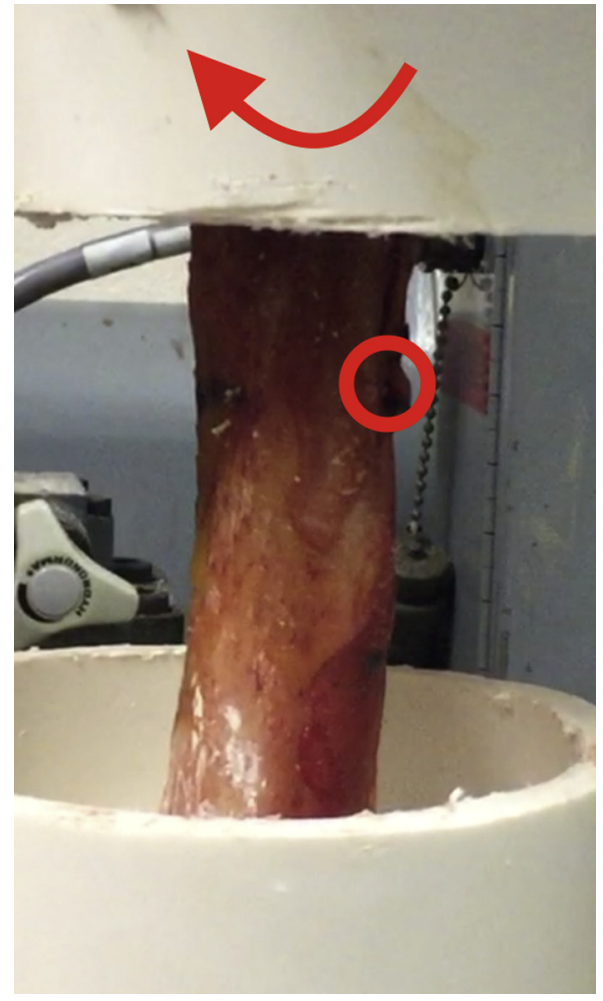

Fig 4. Humerus with subpectoral tenodesis, prior to testing, with tenodesis hole in circle and the arrow showing the direction of torque.

for subpectoral biceps tenodesis, with persistent pain and failure of fixation cited as the most common complications. ${ }^{12}$ No fractures were reported as part of this review. However, several case reports of postoperative fractures have been documented both internationally and in the United States. ${ }^{13,14}$ Most recently, Dein et al. ${ }^{15}$ reported a humeral spiral fracture resulting from pitching 10 months after subpectoral biceps tenodesis performed using a bioabsorbable interference screw. The true incidence of fracture is unknown in the current literature, and as such, it is difficult to surmise any common pattern from the available data. However, in all cases of reported fractures, the fixation method involved a cortical drill hole near the inferior aspect of the pectoralis major tendon. ${ }^{4,5}$ One of the earliest described methods for biceps tenodesis is the key-hole technique, which involves placing the long head of the biceps through a cortical drill hole in the humerus, with a knot being placed in the cut proximal end of the tendon to create a bulbous end to act as fixation. ${ }^{16}$ Techniques have evolved to include fixation with various implants, including metal screws and washers, interference screws, and suture anchors. The impact of a cortical drill hole in diaphyseal bone has been well quantitated by Hipp et al. ${ }^{17}$ In a rabbit model, they showed that a cortical hole sized at $20 \%$ of the diameter of the diaphysis resulted in a $50 \%$ decrease in load to failure (fracture) in torsion. Increasing the size of the hole resulted in a linear decrease in the amount of torque required for fracture.

Of the 2 locations tested in our investigation, the subpectoral cortical drill hole has exceedingly been more commonly described in the literature. The ease of approach and ability to perform the technique in an open manner and with a variety of fixation options have made this location a workhorse location for the many surgeons performing tenodesis. At our institutions, the suprapectoral location at the distal end of the bicipital groove is the preferred location for tenodesis because it can be accessed arthroscopically in conjunction with other procedures being performed in the shoulder during the same operative setting.

Green et al. ${ }^{18}$ published a study showing that clinical outcomes using an implant-free tenodesis technique are similar in patients undergoing suprapectoral tenodesis and those undergoing subpectoral tenodesis, with no reported fracture in the series. However, our biomechanical study has shown that the implant-free biceps tenodesis performed in the subpectoral location has a statistically significantly higher risk of spiral fracture of the humerus, as determined by torsional load to failure, compared with the same technique performed in the suprapectoral region.

The number of specimens available prevented us from performing a direct comparison to the intact

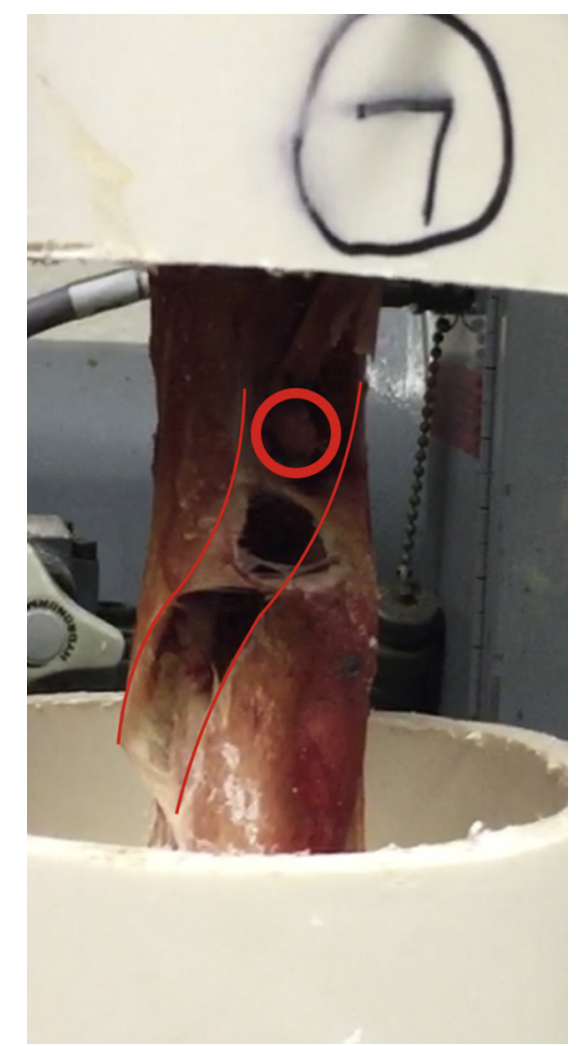

Fig 5. Fracture through subpectoral tenodesis hole (circle), resulting in humeral spiral fracture (red lines). 


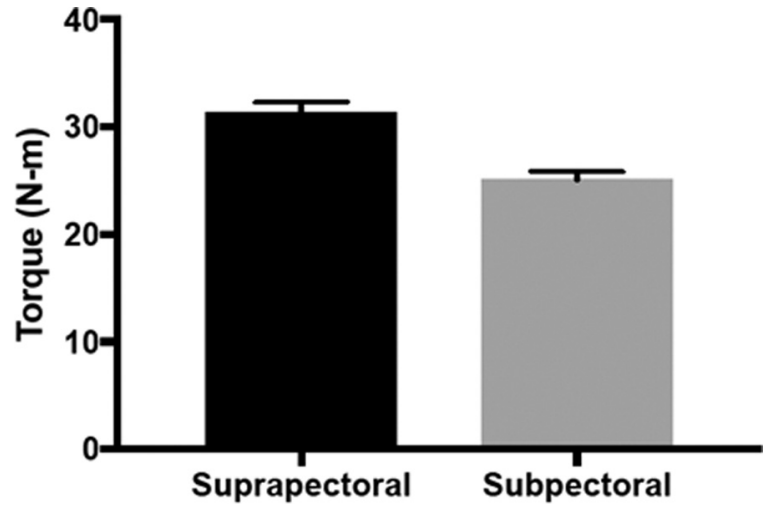

Fig 6. Mean maximal torsion torque required to cause spiral fracture in both bicipital groove and subpectoral tenodesis locations.

humerus as a control. However, such a comparison has already been performed by Beason et al., ${ }^{6}$ and we can extrapolate from their results. When looking at our suprapectoral group, only 2 cases had a fracture through the cortical drill hole. The other 6 specimens all fractured through the intact subpectoral bone. When compared with the control group in the study of Beason et al., the suprapectoral group showed, on average, a $36.15 \%$ reduction in maximum torque to failure (in newton meters). Comparatively, the specimens in the subpectoral group all fractured through the cortical drill hole and had a statistically significantly greater likelihood of fracture; on average, they had a $48.88 \%$ reduction in maximum torque to failure (in newton meters). Therefore, suprapectoral biceps tenodesis is associated with an important reduction in humeral fracture risk compared with subpectoral biceps tenodesis using our implant-free technique when tunnel location is the only variable.

On the basis of our experience, it appears that the cortical bone between the ridges of the bicipital groove serves as a strong point of fixation for the tendon regardless of implant or fixation preference. Preserving the thicker cortex of these ridges by placing the tenodesis hole within the inferior groove, along with the closer proximity to the shoulder joint, as well as the shorter moment arm at the bicipital groove during shoulder internal and external rotation, places it at a lower risk of fracture when performing biceps tenodesis using a method that requires a cortical drill hole. In our opinion, the ridges of the bicipital groove provide stressshielding support similar to an I-beam-type support for the humerus. The results of our biomechanical study show that an increasing external rotation torque applied to a humerus is more likely to result in a spiral fracture of the humerus in the diaphysis, not in the I-beam-reinforced cortical defect in the suprapectoral bicipital groove. The overall torque required to create the humeral spiral fracture was significantly lower in the humeri with subpectoral cortical defects (Fig 7). Furthermore, these specimens all failed at the cortical defect, suggesting that it is a stress riser for fracture. Although a rare complication, fracture should be considered as a possible postoperative complication when performing biceps tenodesis requiring a cortical drill hole, particularly for athletes who perform high torque-generating humeral rotation.

Additional investigation, beyond the scope of our study, looking at different implant options for cortical fixation and their predisposition for fracture would be beneficial. A recent biomechanical ${ }^{19}$ comparison between intramedullary cortical button fixation and interference screw fixation for subpectoral biceps tenodesis showed better in vitro strength of fixation of the intramedullary cortical button. Although this study looked at displacement of fixation with an axial force (not a fracture), it is important to note that the cortical defect created for the button fixation was only $2.6 \mathrm{~mm}$ in diameter, in contrast to $8 \mathrm{~mm}$ for the interference screw in the previous study. A recent biomechanical study comparing the torque-to-fracture rate among 3 specimen groups also showed constructspecific differences. ${ }^{19}$ The specimens were prepared and fractured, with the undrilled contralateral humeri serving as controls, after randomization into 1 of 3 groups: a subpectoral $8-\mathrm{mm}$ tenodesis hole, a similar hole with a PEEK (polyether ether ketone) interference screw, or a PEEK interference screw and tendon. All 3 groups showed a similar decrease in torque required to achieve fracture against the native control specimens. ${ }^{19}$ Specifically evaluating among different implant types and surgical constructs for fracture potential would be beneficial in further quantifying the biomechanical impact these implants have on the humerus to make the best decision on implant choice and location.

\section{Limitations}

The major limitation of this study is the lack of generalizability of the technique. Many surgeons use implants for both suprapectoral tenodesis and subpectoral tenodesis, and the size of the hole remains a concern. Additionally, as new devices become available, surgeons are moving toward creating smaller bone windows, especially

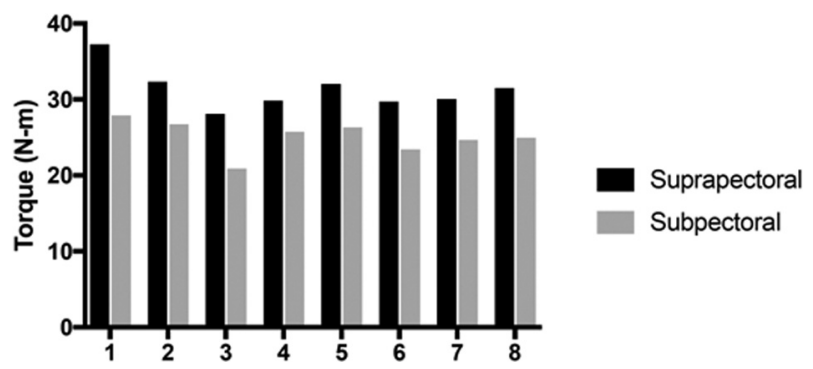

Fig 7. Torque to fracture for each pair of humeri receiving either bicipital groove or subpectoral tenodesis cortical drill holes. 
for subpectoral fixation. Moreover, this study used torsional load to failure as a model for fracture, but the true risk of fracture is multifactorial. Finally, the sample size of 8 cadavers limits statistical power.

\section{Conclusions}

Subpectoral cortical drill holes for biceps tenodesis were shown to be a stress riser for humeral spiral fracture. Suprapectoral cortical drill holes were shown to be significantly less of a stress riser. The amount of torque required to fracture the humerus through the subpectoral drill holes was less than with the suprapectoral drill holes. Only 2 fractures occurred through the suprapectoral tenodesis holes, and significantly more torque was required to create these fractures.

\section{References}

1. Lippmann RK. Frozen shoulder, periarthritis, bicipital tenosynovitis. Arch Surg 1943;47:283-296.

2. Hitchcock HH, Bechtol CO. Painful shoulder. Observations on the role of the tendon of the long head of the biceps brachii in its causation. J Bone Joint Surg Am 1948;30:263-273.

3. Mazzocca AD, Noerdlinger MA, Romeo AA. Mini open and sub pectoral biceps tenodesis. Oper Tech Sports Med 2003; 11:24-31.

4. Sears BW, Spencer EE, Getz CL. Humeral fracture following subpectoral biceps tenodesis in 2 active, healthy patients. J Shoulder Elbow Surg 2011;20:e7-el1.

5. Reiff SN, Nho SJ, Romeo AA. Proximal humerus fracture after keyhole biceps tenodesis. Am J Orthop (Belle Mead NJ) 2010;39:E61-E63.

6. Beason DP, Shah JP, Duckett JW, Jost PW, Fleisig GS, Cain EL Jr. Torsional fracture of the humerus after subpectoral biceps tenodesis with an interference screw: A biomechanical cadaveric study. Clin Biomech 2015;30: 915-920.

7. Virk MS, Nicholson GP. Complications of proximal biceps tenotomy and tenodesis. Clin Sports Med 2016;35:181-188.

8. Golish SR, Caldwell PE III, Miller MD, et al. Interference screw versus suture anchor fixation for subpectoral tenodesis of the proximal biceps tendon: A cadaveric study. Arthroscopy 2008;24:1103-1108.

9. Sergi G, Perissinotto E, Zucchetto M, et al. Upper limb bone mineral density and body composition measured by peripheral quantitative computed tomography in righthanded adults: The role of the dominance effect. J Endocrinol Invest 2009;32:298-302.

10. Sampatacos N, Getelman MH, Henninger HB. Biomechanical comparison of two techniques for arthroscopic suprapectoral biceps tenodesis: Interference screw versus implant-free intraosseous tendon fixation. J Shoulder Elbow Surg 2014;23:1731-1739.

11. Maher SA, Meyers K, Borens O, et al. Biomechanical evaluation of an expandable nail for the fixation of midshaft fractures. J Trauma 2007;63:103-107.

12. Nho SJ, Reiff SN, Verma NN, Slabaugh MA, Mazzocca AD, Romeo AA. Complications associated with subpectoral biceps tenodesis: Low rates of incidence following surgery. J Shoulder Elbow Surg 2010;19:764-768.

13. Friedel R, Markgraf E, Schmidt I, Dönicke T. Proximal humerus shaft fracture as a complication after keyholeplasty. A case report. Unfallchirurgie 1995;21:198-201 [in German].

14. Gyulai M. Humeral fracture after keyhole tenodesis. Magy Traumatol Orthop Helyreallito Seb 1990;33:234-236 [in Hungarian].

15. Dein EJ, Huri G, Gordon JC, McFarland EG. A humerus fracture in a baseball pitcher after biceps tenodesis. Am J Sports Med 2014;42:877-879.

16. Froimson AI, Oh I. Keyhole tenodesis of biceps origin at the shoulder. Clin Orthop Relat Res 1975;1 12:245-249.

17. Hipp JA, Edgerton BC, An KN, Hayes WC. Structural consequences of transcortical holes in long bones loaded in torsion. J Biomech 1990;23:1261-1268.

18. Green JM, Getelman MH, Snyder SJ, Burns JP. Allarthroscopic suprapectoral versus open subpectoral tenodesis of the long head of the biceps brachii without the use of interference screws. Arthroscopy 2017;33:19-25.

19. Mellano CR, Frank RM, Shin JJ, et al. Subpectoral biceps tenodesis with PEEK interference screw: A biomechanical analysis of humeral fracture risk. Arthroscopy 2018;34: 806-813. 